\title{
An Experiment to Introduce pH-responsive Hydrogels for Controlled Drug Delivery: Mechanical Testing
}

\section{Dr. Stephanie Farrell, Rowan University}

Dr. Stephanie Farrell is an Associate Professor of Chemical Engineering at Rowan University (USA). She obtained her PhD in Chemical Engineering from New Jersey Institute of Technology in 1996. Prior to joining the faculty at Rowan in 1998, she was an Assistant Professor of Chemical Engineering and Adjunct Professor of Biomedical Engineering at Louisiana Tech University until 1998. Dr. Farrell has made significant contributions to engineering education through her work in experiential learning, focusing on areas of pharmaceutical, biomedical and food engineering. She has been honored by the American Society of Engineering Education with several teaching awards such as the 2004 National Outstanding Teaching Medal and the 2005 Quinn Award for experiential learning. Stephanie has conducted workshops on a variety of topics including effective teaching, inductive teaching strategies and the use of experiments and demonstrations to enhance learning.

Prof. Jennifer Vernengo, Rowan University

Ms. Madina Yermagambetova, Al-Farabi KazNU

Mr. Peter John Schwalbenberg 


\title{
An Experiment to Introduce pH-responsive Hydrogels for Controlled Drug Delivery: Mechanical Testing
}

\begin{abstract}
In a continuing effort to introduce drug delivery-related experiments for the chemical engineering curriculum, we are developing an experiment to introduce students to $\mathrm{pH}$ responsive hydrogels. These hydrogels have been extensively investigated for controlled drug delivery. By responding to the $\mathrm{pH}$ environment in the body, which changes depending on location and metabolic state, a $\mathrm{pH}$-sensitive drug dosage form is able to modulate drug delivery patterns to meet physiologic requirements and minimize side effects. In a previous experiment for students, hydrogels were prepared and shown to swell more in the neutral $\mathrm{pH}$ environment of the intestines than in the acidic stomach environment. This paper describes an experiment to introduce engineering students in a materials science class to stimuli-responsive polymers for controlled release applications. Students produce a $\mathrm{pH}$-responsive hydrogel using a free-radical solution polymerization and analyze mechanical properties of the gel using tensile testing. The yield stress was greater in the low $\mathrm{pH}$ environment simulating the stomach than it was in the higher $\mathrm{pH}$ environment which simulated the intestines. Young's modulus increased with percentage of monomer in the formulation. Such a system would be useful for the oral delivery of a drug that would be damaged by the low $\mathrm{pH}$ environment of the stomach, such as insulin, and a future experiment will investigate the drug release characteristics of the hydrogels. In addition to learning about $\mathrm{pH}$-responsive drug delivery, students learned concepts of measurements, material properties, design of experiments, data analysis, and engineering design.
\end{abstract}

Keywords: $\mathrm{pH}$ Responsive Hydrogels, Oral Insulin Delivery, Diabetes, Controlled Drug Delivery

\section{INTRODUCTION}

Diabetes is a disease which affects millions of people around the world. It is classified into two major types. Type 1 Diabetes is an auto-immune disease in which, insulin-producing beta-cells within the pancreas are destroyed, resulting in insufficient insulin production by this organ. With type 2 diabetes, the body has developed a rejection to insulin and that glucose uptake cannot be regulated within a patient's muscle and fat cells. When glucose uptake cannot be regulated naturally, blood sugar levels can rise or fall to unacceptable levels and can lead to a lifethreatening diabetic coma if not carefully monitored and treated with regular insulin doses.

Diabetes is a self-managed disease, and patients must administer insulin periodically by injection to maintain blood glucose levels. Injections are painful and inconvenient, and patient noncompliance is a serious concern. The mean rate of insulin usage has been reported to be $77.44 \%$ of the prescribed dose in patients with Type I diabetes who use periodic bolus injections ${ }^{1}$. A convenient and painless oral dosage form could help increase patient compliance; however, insulin will be degraded by the acidic $\mathrm{pH}$ of the stomach before absorption into the blood stream. 
For this reason, researchers have focused on the development of $\mathrm{pH}$ responsive hydrogel drug delivery systems for oral delivery of insulin and other drugs ${ }^{2,3,4,5,6}$.

Hydrogels are extremely hydrophilic crosslinked polymer networks that can absorb large amounts of water. They are largely used in many biomedical applications such as contact lenses, and the physical properties of hydrogels are very similar to living tissues in comparison to other synthetic biomaterials due to their high water content and rubbery properties. Hydrogels have been widely used for drug delivery systems since they allow molecules of different sizes to diffuse into or out of the network for drug loading and release, respectively. Since the polymer chains of different hydrogels contain specific functional groups, hydrogels can be sensitive to changes in the surrounding environment, such as the changes in $\mathrm{pH}$, temperature, and pressures. A successful $\mathrm{pH}$-responsive hydrogel for insulin delivery would exhibit very little swelling in the low $\mathrm{pH}$ of the stomach, thereby restricting the release of the drug. In the higher-pH environment of the stomach, the hydrogel would swell, and the relaxation of the gel network structure would allow release of the drug by diffusion. Furthermore, mechanical properties of hydrogels can be modified by making relatively simple changes to the polymer structure, such as the crosslinked density.

Nakamura et al. reported a hydrogel made with polyethylene glycol chains grafted onto a polymethacrylic acid backbone $\mathrm{p}(\mathrm{MMA}-\mathrm{g}-\mathrm{EG})$ that can be used to transport insulin through the stomach and into the near neutral $\mathrm{pH}$ environment of the intestines, where it can be effectively absorbed into the bloodstream. ${ }^{3}$ While this hydrogel has $\mathrm{pH}$-responsive properties, there are other properties that need to be considered as well. The hydrogels must have the mechanical integrity necessary to make it through the stomach and reach the intestines intact. If the integrity of the gel structure is not maintained during transport through the GI tract, then some insulin could be released in the stomach. In the intestine, the hydrogel must release the drug gradually to avoid a burst of drug in the upper small intestine, which could result in decreased bioavailability by degradation.

Chemical engineers contribute to the design of controlled drug delivery systems which deliver a drug at a desired rate to a desired location in the body. Here, we describe an experiment in which students prepare $\mathrm{pH}$-responsive hydrogels based on $\mathrm{p}$ (MMA-EG) and characterize the network structure of the swollen hydrogel by rubber elasticity experiments. Swelling characteristics of the gel formulations in different $\mathrm{pH}$ environments has been studied previously ${ }^{7}$. In future experiments, hydrogel drug release properties, as a function of formulation and $\mathrm{pH}$, will be examined. Students performing this experiment have the opportunity to vary the hydrogel structure in attempt to optimize the hydrogel for oral insulin delivery. Through this experiment, students will gain hands-on experience in an environment that mimics an undergraduate research experience. They will practice identifying important design variables, in this case, for drug delivery. The students will also practice translating quantitative laboratory measurements into data that can be used to evaluate a design. Lastly, they will learn aspects of polymer design and characterization, which is translatable to other areas of material science and engineering. 


\section{TENSILE Test EXPERIMENT}

In this experiment, students produce $\mathrm{pH}$ sensitive hydrogels by photo-polymerization of a monomer solution containing the photo-initiator dimethoxy propyl acetophenone, the crosslinker, poly (ethylene glycol) methacrylate and monomers methacrylic acid, and poly (ethylene glycol) (n) monomethyl ether monomethacrylate, as described by Tuesca ${ }^{2}$. Students then swell the hydrogels in different $\mathrm{pH}$ solution of Phosphate Buffered Saline solution, cut the gels into strips and use a tensometer to observe the tensile behavior of the hydrogels.

\section{Hydrogel Synthesis}

Materials

- Dimethoxy propyl acetophenone (DMPA)

- Methacrylic Acid (MAA)

- Poly (ethylene glycol) methacrylate (PEGDM)

- Poly(ethylene glycol) (n) monomethyl ether monomethacrylate (PEGMA)

- Ethanol (50wt\%)

- Plain Glass Microslides (75x50 mm)

- Pasteur Pipette

- Micropipettes

- $50 \mathrm{~mL}$ Erlenmeyer flask

- Teflon sheet (0.8 mm thick)

- Small Binder Clips

- 365-nm ultraviolet light (Blak Ray, Upland, CA)

\section{Procedure}

1. In $50 \mathrm{~mL}$ capped vial, MAA, PEGDM, DMPA, PEGMA, ethanol were added in varying amounts described in Table 1. Compositions were chosen based on those proposed by Nakamura et al. ${ }^{3}$ but were modified to produce the hydrogels with the highest degree of mechanical integrity. Table 2 shows the formulation names of the gels with respect to monomer concentration and crosslinker concentration in weight percent. The crosslink density and monomer concentration of the hydrogels was modulated by varying the PEGDM crosslinker amount in the reaction mixture from low to high $(0.173 \mathrm{~mL}$ to $0.865 \mathrm{~mL}$ ) and by varying the amount of $50 \% \mathrm{EtOH}$ solution amount from low to high $(0.487 \mathrm{~mL}$ to $0.6395 \mathrm{~mL}$ to $1.97 \mathrm{~mL}$ to $2.955 \mathrm{~mL})$ in order to investigate the effects of hydrogel properties.

Table 1: Compositions of Hydrogels Fabricated

\begin{tabular}{cccccc}
\hline Formulation & $\begin{array}{c}\text { Mass of } \\
\text { PEGMA }(\mathrm{g})\end{array}$ & $\begin{array}{c}\text { Volume of } \\
\text { MAA(mL) }\end{array}$ & $\begin{array}{c}\text { Volume of } \\
\text { PEGDM }(\mathrm{mL})\end{array}$ & $\begin{array}{c}\text { Mass of } \\
\text { DMPA }(\mathrm{g})\end{array}$ & $\begin{array}{c}\text { Volumeof } \\
\text { EtOH }(\mathrm{mL})\end{array}$ \\
\hline F1 & 0.984 & 1.92 & 0.173 & 0.0292 & 1.97 \\
F2 & 0.984 & 1.92 & 0.865 & 0.03838 & 1.97 \\
F3 & 0.984 & 1.92 & 0.173 & 0.0292 & 0.487 \\
F4 & 0.984 & 1.92 & 0.865 & 0.03838 & 0.487 \\
F7 & 0.984 & 1.92 & 0.173 & 0.0292 & 2.955 \\
F8 & 0.984 & 1.92 & 0.865 & 0.03838 & 2.955 \\
\hline
\end{tabular}


Table 2: Formulation Compositions

\begin{tabular}{ccc}
\hline Formulation & $\begin{array}{c}\text { Monomer Concentration } \\
(\mathrm{wt} \%)\end{array}$ & $\begin{array}{c}\text { Crosslinker Concentration } \\
(\mathrm{wt} \%)\end{array}$ \\
\hline F1 & 50 & 0.4 \\
F2 & 50 & 2.0 \\
F3 & 75 & 0.4 \\
F4 & 75 & 2.0 \\
F7 & 40 & 0.4 \\
F8 & 40 & 2.0 \\
\hline
\end{tabular}

2. The solution was mixed well, ensuring that all of the solid particles dissolved.

3. The solution was clamped and Nitrogen gas was fed through a tube into the solution to remove any remaining air bubbles.

4. Strips of the Teflon sheet were cut and used to keep the two microscope slides spaced $0.8 \mathrm{~mm}$ apart.

5. Binder clips were used to hold the microscope slides together.

6. Using the Pasteur pipette, the monomer solution was transferred between the microscope slides to completely fill the space between slides.

7. The microscope slides with solution were then placed underneath the UV lamp and the lamp was turned on.

8. The solution was left underneath the UV lamp from 20 minutes to 45 minutes depending on the amount of cross linker used.

9. The UV lamp was turned off, and the hydrogel was removed from the microscope slides.

10. The hydrogel was placed in DI water for 24 hours to rinse off any possible residual monomer solution that did not polymerize.

\section{Tensile Testing}

\section{Materials}

- Synthesized hydrogels

- Phosphate buffered saline (PBS) solution, $\mathrm{pH} 2.2,6.8$.

- $2 \mathrm{~N}$ Shimpo Force Guage, Model:FGV-0.5XY

- $1000 \mathrm{~N}$ Shimpo Force Guage, Model: FGV-200 HX

- Shimpo Tensometer

- Vaseline ${ }^{\circledR}$

- Q-tips

- 3M Fine grain sand paper with fabric base

- Clamp Base

- Tensile Clamps

- PC with Estand ${ }^{\circledR}$ Software

- Superglue gel 


\section{Procedure}

1. Hydrogels with various formulations were put into two different $\mathrm{pH}$ buffer solutions $(\mathrm{pH}=2.2$ or 6.8$)$ for three hours prior starting the tensile test.

2. The $2 \mathrm{~N}$ force gauge (Shimpo Corporation Instrument Division, Model: FGV-0.5XY) was set up on the tensile test machine while screwing on the clamps onto the force gauge. (Note that for the stiffer hydrogel samples, the 1000N force gauge (Model: FGV-200HX) was used)

3. Fine grain Sandpaper were cut into $1 \mathrm{~cm}$ based trapezoidal pieces. Four trapezoidal pieces of sandpapers were needed per hydrogel sample.

4. Hydrogels were taken out of the buffer solutions were cut into "dog boned" shaped strips with an approximate dimension of $1.3 \mathrm{in}$. The width of the sample was measured at the top, middle, and bottom to give an average width. The thickness of the sample was also measured.

5. Vaseline ${ }^{\circledR}$ was applied to the exposed "dog boned" are of the hydrogel on all sides to prevent the hydrogels from equilibrating with air and drying out

6. Superglue gel was used to adhere the sandpaper trapezoidal pieces to each end on both sides of the hydrogel.

7. The sandpaper strips were left to dry for approximately 15 minutes

8. After drying, the two ends of the hydrogel were clamped to the tensometer. The nonadhered areas of the sandpaper were the only material that was clamped.

9. The force gauge was turned on following the tensometer. The E-stand ${ }^{\circledR}$ Software was then started on the computer.

10. Tear and set home tabs were clicked on the program before starting the tensile test. Also the capture data tab was also clicked before starting and the up speed was $15 \mathrm{~mm}$ per minute.

11. The UP button was clicked to start the tensile test and waited until the hydrogel sample was completely torn apart. The STOP button was clicked in order to stop the force gauge from pulling the broke apart gel sample.

12. The data was saved into Excel program for further data analysis and physical observation of the sample was recorded as well.

\section{Experimental Calculations}

In order to analyze the data from the Tensile Test, Stress vs. Strain Curves needed to be constructed for each type of hydrogel gel. Stress is defined in Equation 1 where Stress is equal to the upward force in units of $\mathrm{N}$ divided by the cross sectional area of the hydrogel in units of $\mathrm{m}^{2}$. This ratio accounts for the variation in hydrogel dimension and thus allows each sample's stress value to be compared. To calculate strain, the difference in the length of the "dog-boned" area was divided the original length as shown in Equation 2. 


$$
\begin{gathered}
\text { Stress }=\frac{\text { Force }}{A_{C}} \\
\text { Strain }=\frac{\Delta L}{L_{0}}=\frac{L-L_{0}}{L_{0}}
\end{gathered}
$$

In addition to determining the maximum stress value for a particular gel formulation, the stiffness of the gel was also measured. Within the elastic deformation section of the Stress vs. Strain curve, which exhibits a linear trend, the slope can be found which is equivalent to Young's Modulus as shown in Equation 3. The higher the Young's Modulus, the stronger the material and the more resistance the material shows to stretching.

$$
\text { Young's Modulus }=\frac{\text { Stress }}{\text { Strain }}
$$

\section{RESULTS AND DISCUSSION}

Figure 1, Figure 2, and Figure 3 show the Average Stress vs. Strain Curves for the Formulations 1,4 , and 7 respectively, analyzed at the two different $\mathrm{pH}$ values of 2.2 and 6.8 . In a $\mathrm{pH}$ of 2.2 Formulation 1 gave an average maximum yeild stress of approximately $5.3 \times 10^{5} \mathrm{~N} / \mathrm{m}^{2}$ while in a $\mathrm{pH}$ of 6.8 , the average maximum yeild stress was $3.5 \times 10^{5} \mathrm{~N} / \mathrm{m}^{2}$ (Figure 1). Similar trends can be seen in for Formulations 4, and 7 indicating that at a lower $\mathrm{pH}$, the hydrogel nework is stronger, hence a greater maximum force. In both Figure 1 and Figure 3, which correlate to 50\% monomer and $40 \%$ with $0.4 \%$ crosslinker ( $\mathrm{F} 1$ and F7), the hydrogel yeilds a longer strain before material failure compared to curve exhibited by the hydrogel with $75 \%$ monomer and $2 \%$ crosslinker composition, (F4). This indicates that as the network becomes more linked and dense with polymer chains, the material becomes more brittle at a lower $\mathrm{pH}$ and resists stretching. For Formulations 2, 3, 8, the hydrogel samples were too stiff for the $2.0 \mathrm{~N}$ load guage and were not stiff enough for the $1000 \mathrm{~N}$ load guage making it impossible to obtain usable data. These trials will be completed when a load gauge in the appropriate intermediate range is obtained. This will be valuable in obtaining statistical data that will determine optimum formulation for a durable hydrogel formulation. Another consideration in the experimental procedure is that the hydrogels were sensitive in the "dog boning" procudure and would break at any tears toward the end caused by nicks. An alternative procedure for cutting the hydrogels will be explored. 


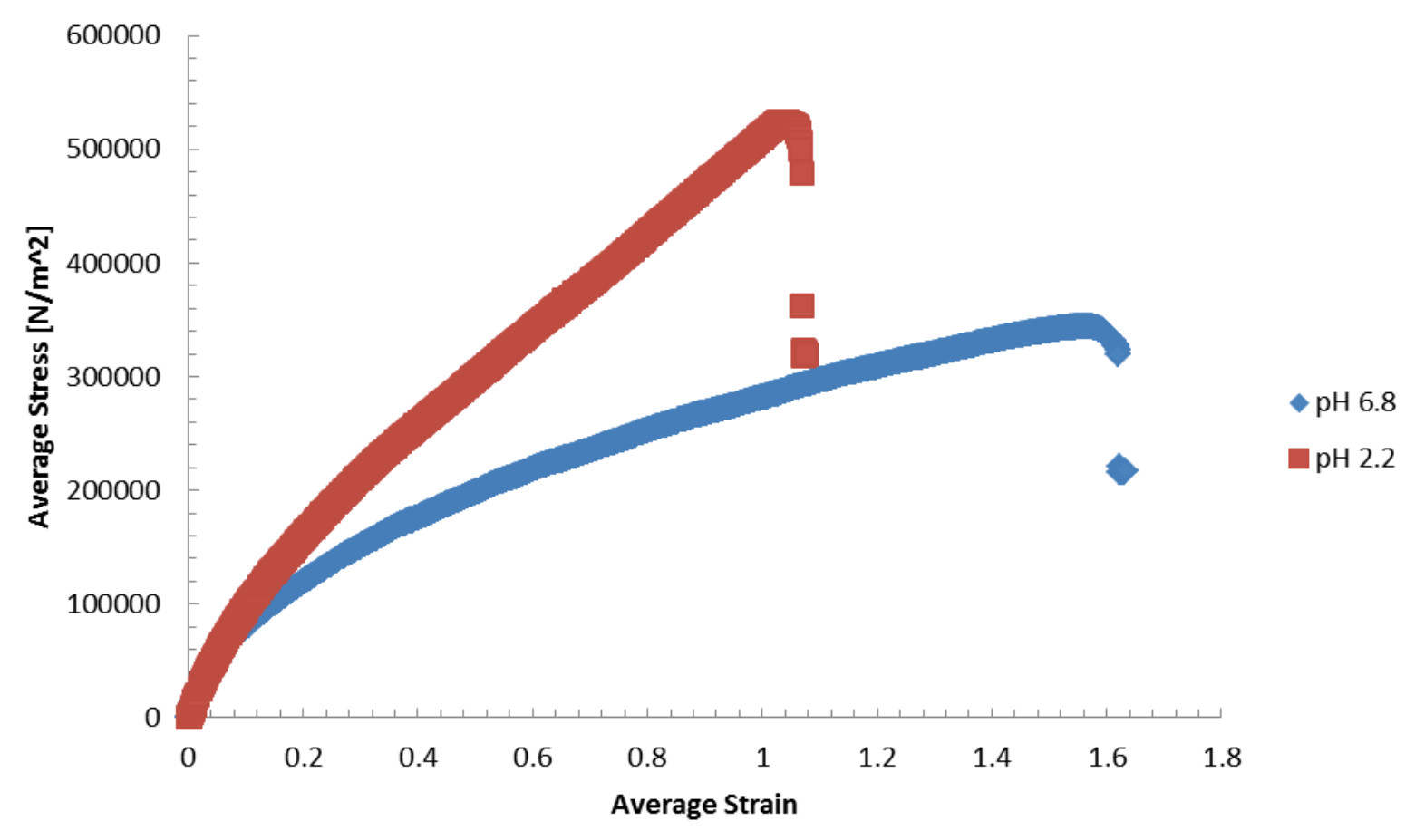

Figure 1: Average Stress vs. Strain Curves of Formulation 1 at $2 \mathrm{pH}$ values

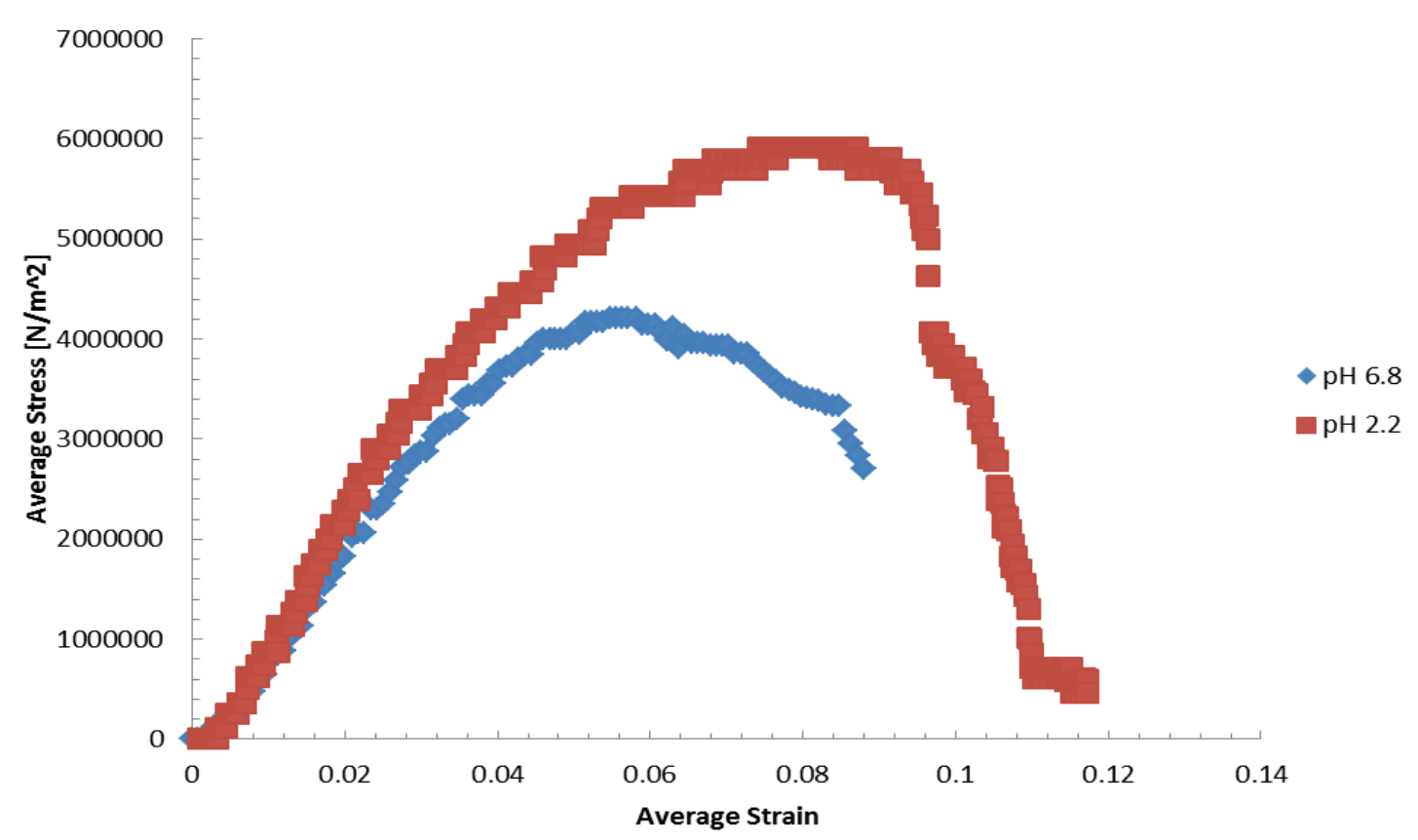

Figure 2: Average Stress vs. Strain Curves of Formulation 4 at $2 \mathrm{pH}$ values 


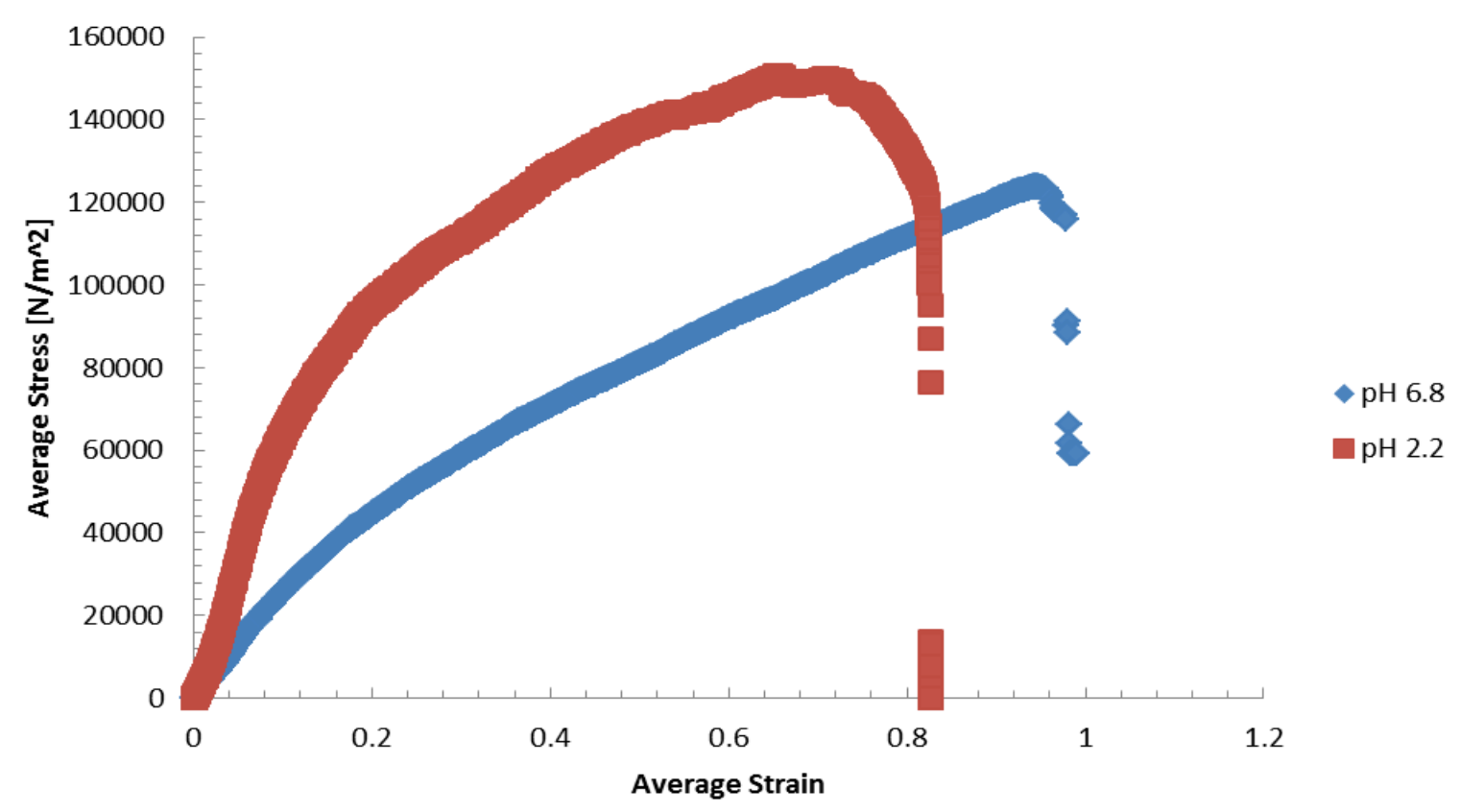

Figure 3: Average Stress vs. Strain Curves of Formulation 7 at $2 \mathrm{pH}$ values

To illustrate a clear comparison of F1, F4, and F7 in each specific $\mathrm{pH}$ solution, all three curves were plotted together in Figure 4 and Figure 5. In each $\mathrm{pH}$ buffer solution, Formulation 4, the strongest hydrogel, demonstrated a significantly greature failure point within the least amount of strain.

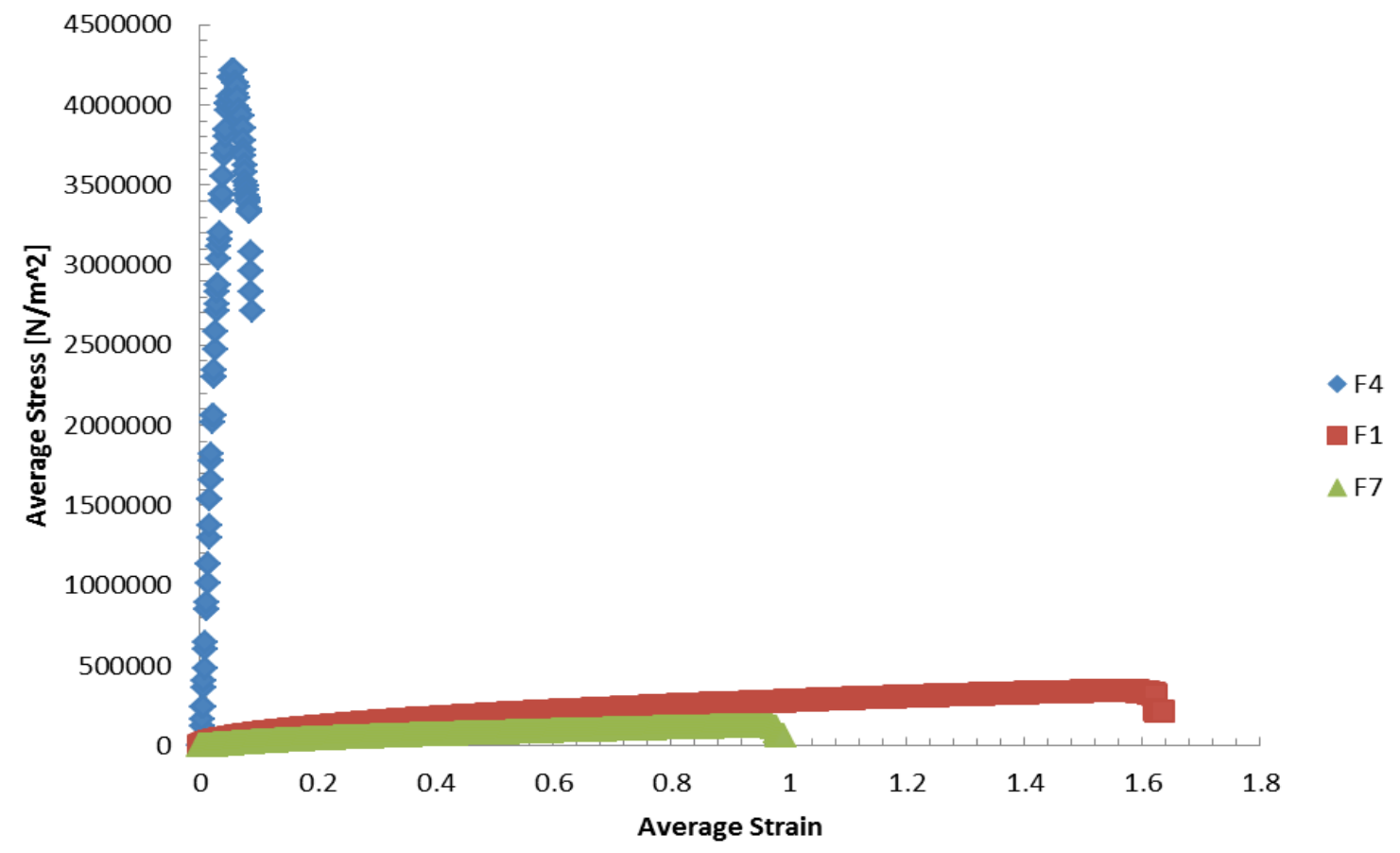

Figure 4: Average Stress vs. Strain Curves of Formulations 1, 4, 7 at a pH of 6.8 


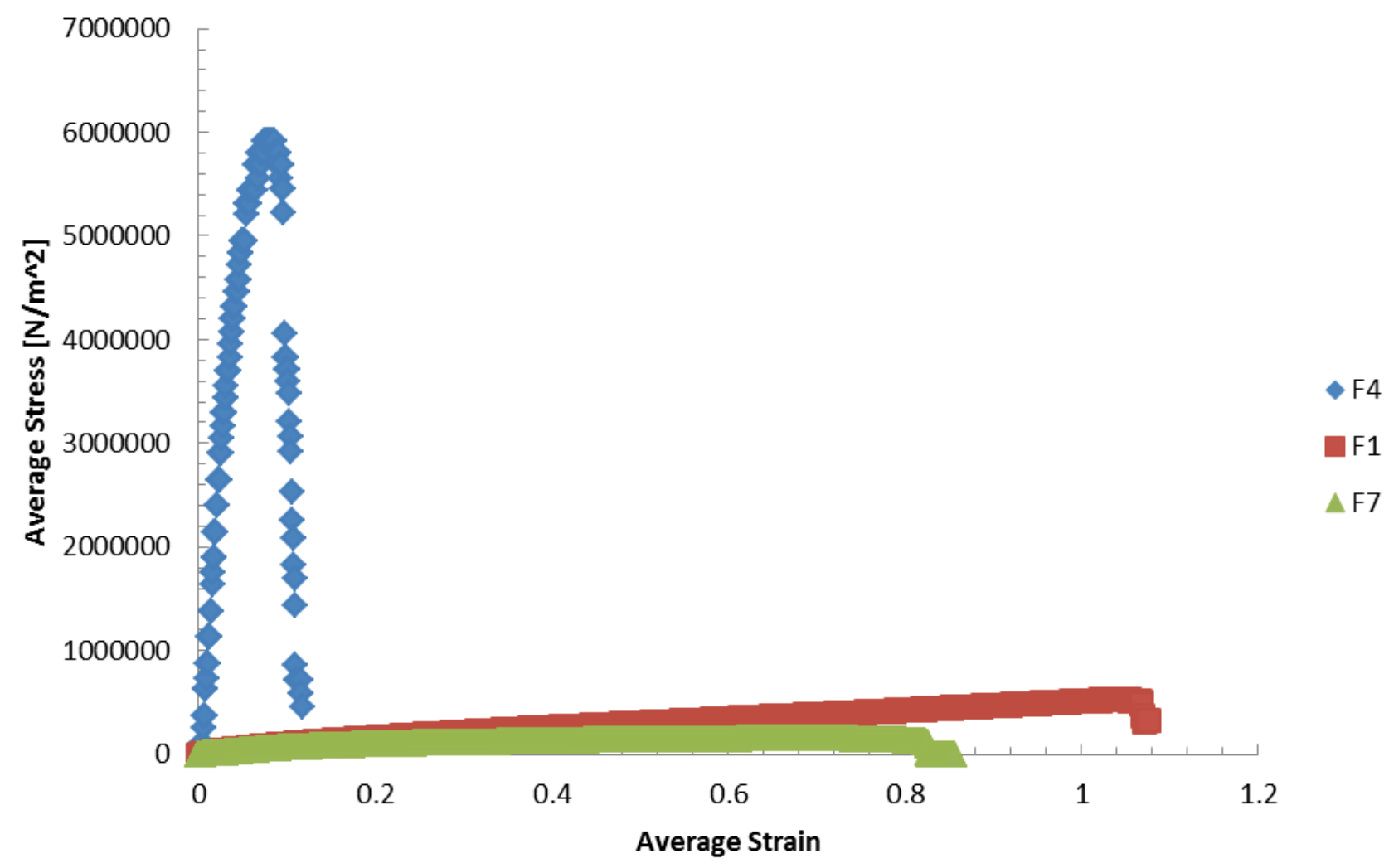

Figure 5: Average Stress vs. Strain Curves of Formulations 1, 4, 7 at a pH of 2.2

Shown below in Table 3 are the average Young's Modulus values for the forumulations that produced legible Stress vs. Strain curves. These averages were based on the initial slopes of the curve which accounted for roughly $5 \%$ of the total curve. Each sample's slope was taken and averaged to produce the following values. One can see that as the percentage of monomer increases, the modulus increases. This correlates to the polymer network containing more monomer in the back bone of the network which would cause an increase in support. Another key observation in these results is that the modulus value is greater for those formultions exposed to the lower $\mathrm{pH}$ value. With less swelling, the polymer network forms a tighter hold which would increase the strength of the hydrogel. 
Table 3: Young's Moduli for Formulations 1, 4, and 7

\begin{tabular}{|c|c|}
\hline Composition & $\begin{array}{c}\text { Average } \\
\text { Young's Modulus }\left[\mathrm{N} / \mathrm{m}^{2}\right]\end{array}$ \\
\hline $\begin{array}{c}\text { 40\% Monomer } \\
\text { o.4\% Crosslinker } \\
\mathrm{pH}=2.2\end{array}$ & $4.006 \mathrm{E}+06$ \\
\hline $\begin{array}{c}\text { 40\% Monomer } \\
0.4 \% \text { Crosslinker } \\
\mathrm{pH}=6.8\end{array}$ & $1.206 \mathrm{E}+06$ \\
\hline $\begin{array}{c}50 \% \text { Monomer } \\
0.4 \% \text { Crosslinker } \\
\mathrm{pH}=2.2\end{array}$ & $1.187 \mathrm{E}+06$ \\
\hline $\begin{array}{c}50 \% \text { Monomer } \\
0.4 \% \text { Crosslinker } \\
\mathrm{pH}=6.8\end{array}$ & \\
\hline $\begin{array}{c}75 \% \text { Monomer } \\
2.0 \% \text { Crosslinker } \\
\mathrm{pH}=2.2\end{array}$ & $6.209 \mathrm{E}+05$ \\
\hline $\begin{array}{c}75 \% \text { Monomer } \\
2.0 \% \text { Crosslinker } \\
\mathrm{pH}=6.8\end{array}$ & $1.926 \mathrm{E}+08$ \\
\hline
\end{tabular}

\section{SUMMARY AND RECOMMENDATIONS}

In this paper, we present a laboratory activity on biomaterials and drug delivery for undergraduate engineering students. This aspect of our project focused on structure-property relationships in $\mathrm{pH}$ sensitive hydrogels for oral insulin delivery. In upcoming work, drug release properties will be evaluated as a function of crosslink density and monomer concentration as well as a complete tensile data collection. Through this hands-on activity, students will not only develop skills specific to drug delivery and biomaterials, but in data acquisition and analysis and engineering design. The laboratory was implemented into the chemical engineering materials science course. Pre and post-tests will be used to gauge student mastery of learning outcomes specific to the field of biomaterials science and those set forth by ABET for undergraduate chemical engineering programs

\section{ACKNOWLEDGEMENT}

This material is based upon work supported by the National Science Foundation under Grant Nos. DUE 1140631 and ECC 0540855. 


\section{References:}

${ }^{1}$ Cramer, J.A., A systematic review of adherence with medications for diabetes, Diabetes Care, Vol 27, Issue 5, (2004), pp. 1218-1224.

2 Tuesca, Anthony, Synthesis, characterization, and application of polyethylene glycol modified insulin for oral delivery using complexation hydrogels, doctoral dissertation, Drexel University, February 2008.

${ }^{3}$ Koji Nakamura, Robert J. Murray, Jeffrey I. Joseph, Nicholas A. Peppas, Mariko Morishita, Anthony M. Lowman. Oral insulin delivery using P(MAA-g-EG) hydrogels: effects of network morphology on insulin delivery characteristics. J. Control. Release, Vol. 95, Issue 3, (2004). pp. 589-599

${ }^{4}$ Piyush Gupta, Kavita Vermani, Sanjay Garg. Hydrogels: from controlled release to pH-responsive drug delivery. Drug Discovery Today, Vol. 7, Issue 10,(2002), pp 569-579.

${ }^{5}$ Ferreira L. and Vidal, MM, Evaluation of poly(2-hydroxyethyl methacrylate) gels as drug delivery systems at different pH values. Int. J. Pharm.194 (2000), pp. 169-180.

${ }^{6}$ Bilia, A. V. Carelli, G. Di Colo, and E. Nannipieri, In vitro evaluation of a pH-sensitive hydrogel for control of GI drug delivery from silicone-based matrices. Int. J. Pharm. 130 (1996), pp. 83-92.

${ }^{7}$ Farrell, S. and J. Vernengo, An experiment to introduce PH-responsive hydrogels for controlled drug delivery, Proceedings of the 2012 ASEE Annual Conference, June 2012. 